\title{
Application of Mass Customization in the Construction Industry
}

\author{
Kim Noergaard Jensen, Kjeld Nielsen, Thomas Ditlev Brunoe \\ Department of Mechanical and Manufacturing Engineering, Aalborg University \\ $\mathrm{knj} @ \mathrm{~m}$-tech $\cdot \mathrm{aau} \cdot \mathrm{dk}$
}

\begin{abstract}
This paper is based on the assumption of that Danish companies in the construction industry can benefit from the advantages inherent in the use of Mass Customization.

Mass Customization is a production strategy that focuses on offering customized products, at a low cost. Exploiting of principles in Mass Customization, like standardization of modules, configuration and flexible production, makes it possible using a variety of tools to composing and producing customized products for commercializing at similar conditions as serial produced standard products.

The research contribution of the project is to clarify the situation of "where we are today" and to determine the development potential for the companies, and since it is early days in the project, the statistical material will improve when involving more companies in the workshops.
\end{abstract}

Keywords: Mass Customization, Construction Industry, Increased Productivity,

\section{Introduction}

The construction industry employs approx. 25\% of the private workforce in Denmark, and the industry is currently facing a number of challenges, including a lot of burden on costs that makes companies continuously searching for initiatives to reduce production costs to meet competition.

The productivity in the Danish construction industry has doubled since 1966, which is significantly less than the construction industry in other European countries, but also less compared to other sectors in Denmark (fig 1).

Increasing industrialization has achieved results in other industries in Denmark in terms of increasing productivity. We interpret increased industrialization as increasing utilization of new technologies for production, streamlining and constant development of production processes and other correlated support processes.

One of the reasons that construction industry having less degree of industrialization is that construction industry, opposite the standardized products that formed the basis for the industrial revolution, is very different and often one-of-a-kind, and therefore it may seem difficult or challenging to streamline and optimize processes as "assembly line production" [1], [3]. However, over the past decades, industrial production has

adfa, p. 1, 2011.

(C) Springer-Verlag Berlin Heidelberg 2011 


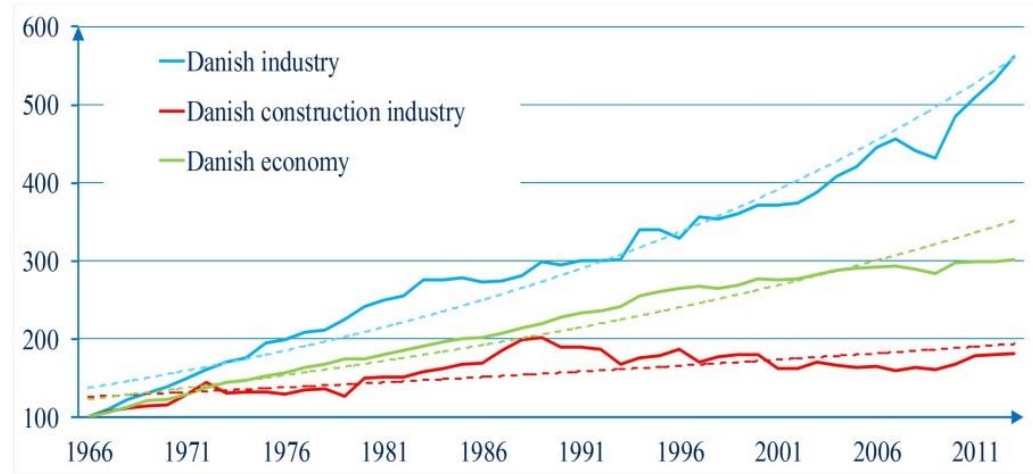

Fig. 1. Labor productivity by industry, unit cost and time (Year (index $1966=100$, 1966-price level chain figures) [Statistics Bank NATP23])

gone through a process in which more and more companies are offering customized products [9] "at a price near Mass Production [1] "under the production strategy called Mass Customization [7]. The construction industry's traditional demand for customization e.g. distinctive architecture, function, quality, timeframe, environment, is difficult to reconcile with traditional industrialization (standardization, Mass Production). However, Mass Customization characterizes the requirement of flexible products and processes.

In Mass Customization, applied IT tools like automated business process, product configurators, flexible production processes, and product design allows customization where the end customer can choose from millions of product variants and chose the flavor that just matches unique needs for a low price (cost minimization) [5], [7]. These principles are widely and with great success used in e.g. automotive and computer industry [7], [8].

The applied principles behind Mass Customization enable industrial production of customized products [7], and for the construction industry, a great potential may result in applying these principles, as they face the challenge of producing products with high variance and often one-of-a-kind production [5].

Some segments of the construction industry have already implemented parts of Mass Customization where manufactures of windows, doors, kitchen, housing, and bath products for example offering customized products manufactured in a highly automated and flexible production [2], [4].

A current research project has as one of the objectives to increase knowledge and utilization of Mass Customization in Danish construction industries. The objectives are to make Danish companies in the construction industry capable of implementing the principles of Mass Customization leading to increasing industrialization and productivity.

Recent research shows that companies that utilize Mass Customization must have three fundamental capabilities [8]: 
1. "Solution Space Development; the ability to identify how customer requirements are different and develop products that can effectively adapt to these individual requirements through the product platforms or modularization"

2. "Choice Navigation; the ability to guide the customer to select or configure the product that matches his requirements"

3. "Robust Process Design; the ability to efficiently to produce a large batch of products at low cost that typically is achieved by using the flexible manufacturing systems"

Furthermore, the objectives of the project are to develop these three capabilities for companies in the construction industry by utilization of Mass Customization. These companies will be able to realize a greater growth potential, as they will be able to meet the needs from their customers faster and at lower cost [6].

This may also lead to, and increase in the ratio of exports in those companies, because development of capabilities focusing on a greater share of the market [6].

In relation to the three capabilities, the project includes for each of the companies the following activities organized as conferences, networking, and workshops [8]:

- Solution Space Development:

- Make a screening of the current product structure to determine to which extent modularization id used and identifying the variety in the product portfolio.

- Choose areas, e.g. specific parts of products where the company can benefit from using modularization in a short and a long term to gain competitive advantages.

- Choice Navigation

- Identify opportunities for application of product configuration for sale and specification of products in a sales situation, and

- To develop prototypes of configurators

- Robust Process Design

- Analysis of current production processes to identify the potential of automation (business processes and physical production processes) and the use of flexible manufacturing equipment

- General:

- Together with the company, to conduct workshops where the knowledge gained about the tools and methods incorporated on selected specific areas.

The participating companies will during the project gain knowledge and skills in tools and methods to utilize, so after the participation they are able to properly using the tools for Mass Customization.

The innovation potential of the participating companies is to be able to meet the customers demand for unique products cost effectively, by:

- Develop new and more cost-effective business and production processes

- Develop products customized more efficiently than traditional building products.

Apart from the innovation objectives in the project, there are also formulated research objectives. The research objectives are to analyze how companies in the Danish construction industry can typically benefit from utilizing mass customization prin- 
ciples. Furthermore, the objective is to identify which specific challenges these companies typically face when implementing mass customization, since it is expected by the authors that these challenges are different from those met in the general manufacturing industry. Finally, the objective is to adapt methods for enhancing the performance within mass customization, so that they are applicable in the construction industry. This paper addresses the first two research objectives, by discussing the potential in applying mass customization and some of the initial challenges.

This paper summarizes the result of two workshops done in corporation with a number of companies that are a part of the supply chain of the construction industry. The workshops are mapping the involved companies according to their current and their expected future position of Mass Customization relative to their competitors, and expectations of their customers.

The innovative contribution for all of the participating companies is to increase the knowledge of tools and methods used for Mass Customization, which leads to increasing productivity. The research contribution is to clarify the situation of "where we are today" and to determine the development potential for the companies.

\section{Workshop approach}

The methodology includes a number of companies participating in workshops concerning the following themes of Mass Customization:

- Mapping Mass Customization

- Mapping Product Varity

The findings from the workshops summarizes in section "4. Results" and the content of the workshops are as described in the following.

\subsection{Variety-Volume Mapping of Mass Customization}

Each company was at the workshops asked to plot in a coordinate system (shown in fig. 2 and fig. 3), the following questions:

1. What does our customers expect?

2. Where are the competitors?

3. Map the current position (As-Is). Where are we now?

4. Map the future desirable position (To-Be). Where would we like to be?

\section{Workshop Participants}

A number of companies have participated in the two workshops, and the companies represent the following types of industries:

A company makes roof tiles, wall bricks and pre-stressed brick beams for the whole market of Northern Europe. By using the technique with pre-stressed bricks, 
one can produce brick beams for large spans, roofs and brick elements that are not possible by traditional bricks. The company has acquired a number of production facilities placed different places in Denmark. The company makes standard products as well as customized products.

A company has specialized in a new generation of High Performance Precast Concrete, which can achieve minimalistic and elegant design. The precast High Performance Concrete products are unique because they combine the free shape ability of concrete, the strength of steel and a higher durability than both steel and normal concrete. The company is the largest producer of precast Compact Reinforced Composite and one of the world market leaders in structural applications of Ultra High Performance Fiber Reinforced Concretes.

A company makes products for clearing the air, to design, develop and make available kitchen hoods with innovative technology to strive for maximum extraction efficiency with minimum noise levels. The company has been at the forefront of finding the best solutions to any specific ventilation needs. The range of the products is among the most comprehensive available. Regardless of the style of the kitchen or personal preferences, they have a model that will suit the needs for ventilation as well as design.

A company is the world's leading manufacturer of stainless steel machine feet, and the company has an efficient and fully automated machinery, which enables to offer the customers a comprehensive range of machine feet in stainless steel and reinforced polyamide for adjustment, stabilization and vibration control of all types of machinery and equipment. Products are to meet the hygienic requirements applying in Europe and the USA. The company is providing hygienic solutions for machinery and equipment in the food industry and pharmaceutical industry. Flexibility is an important factor in offering customized solutions. It may be of minor adjustments of standard products or a completely different design of the products used on the machines.

A company is a modern sign company, which is a total supplier of designer products in signage solutions, digital signage and Way Showing Services and street furniture, including bike racks, information creation, flags and flagpoles and mailboxes. The company have experience in creating the visual identity for companies, and institutions sending signals to employees, customers, visitors and residents. Among the clients are private companies, business parks, business centers, nursing and senior services, hospitals, education, housing associations, churches and public administration buildings.

A company offers easy and intuitive way finding solutions designed for large buildings and campuses as well as resource booking and visitor management tools. The solutions enable great user experiences in flexible, dynamic indoor environments, and make it easy to book available resources like meeting or conference rooms. The company improves the guest experience in a building marked, as the solutions will welcome the guest, all the way from entrance to he sits comfortably organized in the right meeting room. The company has the headquarters, showroom and development department in Denmark, as well as office and sales department in the US. 
A company offers a wide range of doors and parties, and all the doors are available with either painted, laminated or veneered surface. They are making fire protected doors in different categories, and soundproof doors in different audio category.

\section{$4 \quad$ Results}

The results of the workshops are presented briefly here:

\subsection{Variety-Volume Mapping of Mass Customization for Different Companies}

Fig. 2 shows the positioning of the different companies according to the questions asked (number 1 to 4 . See chapter 2.1). The different companies are marked with different colors and an arrow that illustrate the movement from "As-Is" to "To-Be"; meaning "where they are now" and "where they would we like to be in the near future". A precise pattern shows that all of the participating companies see themselves moving towards a higher degree of Mass Customizing in the future, by being able to offer the customers more variants than today. Furthermore, it looks like that everyone consider themselves better than the competitors. Generally, it seems that everyone have a knowledge about what their customers want, even though there is no precise pattern of how each company are positioning the company "As-Is" or "To-Be" relative to the customer need, and the competitors.

\subsection{Variety-Volume Mapping Internally in Companies}

After analyzing cross-company, if the individual companies had intentions to move

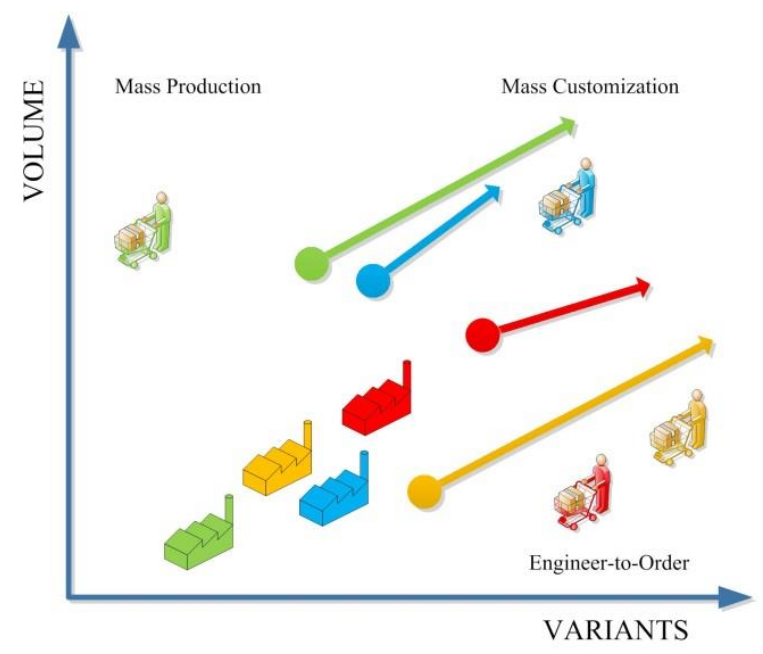

Fig. 2. Mapping the position for the different companies. 


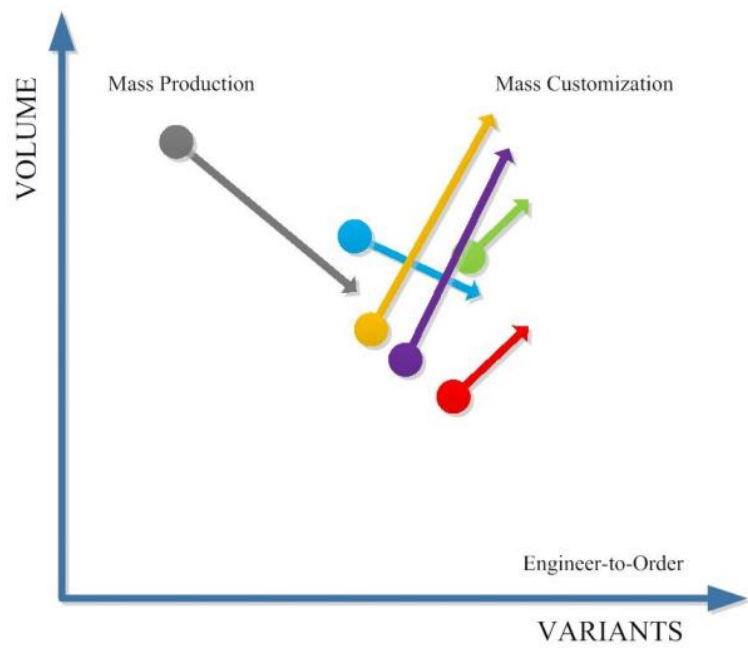

Fig. 3. Map the Positioning relative to volume and variants for different persons within the same company.

towards Mass Customization, it was analyzed whether there was internal agreement on which way the companies should change.

Fig. 3 shows for one company the positioning made by different persons within the same company, according to the questions asked (number 3 to 4 , see chapter 2.1). The different persons are marked with different colors and an arrow that illustrate the individual perception of the company's "As-Is" and "To-Be" position. Even though, there is some variation in opinions, there seems to be a trend showing a movement towards a higher degree of Mass Customizing in the future. However, disagreement on which way the company should move, can be critical for the implementation of a Mass Customization, as with the implementation of any strategy. Hence, it seems that this particular company will need to align opinions on company strategy in relation to Mass Customization. This picture is general to many of the companies taking part in the project and is thus considered a general tendency within the industry, which must be addressed.

\section{Discussion}

The results indicate that each company did the mapping differently and personnel within the same company have different perception of how to make the positioning, even though all participants prior to the workshops have gone through the same introduction to Mass Customization philosophy and workshop introduction.

This may be due to many reasons, e.g. individual skills, background, role within the company, knowledge about products, customers, competitors, and knowledge about internal business strategy, and of course different understanding of the workshop. 
The innovative contribution for all of the participating companies is as a part of the collaboration during the project to increase the knowledge of tools and methods used for Mass Customization, which leads to increasing productivity. Therefore, by moving towards the "To-Be" position, it will improve the individual company and make small improvements to the Danish construction industry by implementing the principles of Mass Customization to increasing productivity.

The research contribution of the project is to clarify the situation of "where we are today" and to determine the development potential for the companies, and since it is early days in the project, the statistical material will improve when involving more companies in the workshops.

We experienced a need for intensive information and knowledge prior to any Mass Customization workshop or development process to ensure that everyone are in alignment, well informed by sufficient knowledge to contribute to the Mass Customization process. Therefore, we are recommending a systematic process to inform the parties with necessary information and knowledge.

\section{References}

1. Batchelor, R.: Henry ford, mass production, modernism, and design, Vol. 1. Manchester University Press (1994)

2. Benros, D., \& Duarte, J.: An Integrated System for Providing Mass Customized Housing. Autom. Constr., 18 (2009) 310-320

3. Bohnstedt, K. D.: Enabling Facilitation of Mass Customization Via Partnering in the Construction Industry. (2014) 179-188

4. Dean, P., Tu, Y., Xue, D.: A Framework for Generating Product Production Information for Mass Customization. The International Journal of Advanced Manufacturing Technology, 38 (2008) 1244-1259

5. Dean, P., Tu, Y., Xue, D.: An Information System for One-of-a-Kind Production. Int J Prod Res, 47 (2009) 1071-1087

6. Jiao, J., Ma, Q., Tseng, M. M.: Towards High Value-Added Products and Services: Mass Customization and Beyond. Technovation, 23 (2003) 809-821

7. Pine, B. J.: Mass customization: The new frontier in business competition. Harvard Business School Press, Boston, Mass. (1993)

8. Salvador, F., De Holan, P. M., Piller, F.: Cracking the Code of Mass Customization. MIT Sloan Management Review, 50 (2009) 71-78

9. Walcher, D., \& Piller, F. T.: The customization 500. 1st edition edn. Lulu Press, Aachen (2011) 